\title{
High expression levels of egfl7 correlate with low endothelial cell activation in peritumoral vessels of human breast cancer
}

\author{
DIANE PANNIER ${ }^{1,2^{*}}$, GÉRALDINE PHILIPPIN-LAURIDANT ${ }^{1,2^{*}}$, \\ MARIE-CHRISTINE BARANZELLI ${ }^{1}$, DELPHINE BERTIN ${ }^{1}$, EMILIE BOGART ${ }^{1}$, VICTOR DELPRAT ${ }^{2}$, \\ GAËLLE VILLAIN $^{2}$, VIRGINIE MATTOT ${ }^{2}$, JACQUES BONNETERRE ${ }^{1}$ and FABRICE SONCIN ${ }^{2}$ \\ ${ }^{1}$ Senology Department, Oscar Lambret Center, Université de Lille, 59020 Lille; \\ ${ }^{2}$ Institut Pasteur de Lille, Centre National de la Recherche Scientifique UMR8161, Université de Lille, 59000 Lille, France
}

Received October 5, 2015; Accepted May 24, 2016

DOI: $10.3892 / 01.2016 .4791$

\begin{abstract}
Tumor blood vessels participate in the immune response against cancer cells and we previously used pre-clinical models to demonstrate that egfl7 (VE-statin) promotes tumor cell evasion from the immune system by repressing endothelial cell activation, preventing immune cells from entering the tumor mass. In the present study, the expression levels of egfl7 and that of ICAM-1 as a marker of endothelium activation, were evaluated in peritumoral vessels of human breast cancer samples. Breast cancer samples (174 invasive and 30 in situ) from 204 patients treated in 2005 were immunostained for CD31, ICAM-1 and stained for egfl7 using in situ hybridization. The expression levels of ICAM-1 and egfl7 were assessed in peritumoral areas using semi-quantitative scales. There was a strong and significant inverse correlation between the expression of ICAM-1 and that of egfl7 in CD31 $1^{+}$blood vessels. When the ICAM-1 score increased, the egfl7 score reduced significantly $(\mathrm{P}=0.004)$, and vice-versa (Cuzick's test for trend across ordered groups). In order to determine which gene influenced the other gene between egfl7 and ICAM-1, the expression levels of either gene were modulated in endothelial cells. Egfl7 regulated ICAM-1 expression while ICAM-1 had no effects on egfl7 expression in the same conditions.
\end{abstract}

Correspondence to: Dr Fabrice Soncin, Institut Pasteur de Lille, Centre National de la Recherche Scientifique UMR8161, Université de Lille, 1 Rue du Pr. Calmette, 59000 Lille Cedex, France

E-mail: fabrice.soncin@ibl.cnrs.fr

Abbreviations: B2M, $\beta 2$-microglobulin; DCIS, ductal carcinoma in situ; egfl7, EGF-like domain-containing protein 7; ICAM-1, intercellular adhesion molecule-1; IDC, invasive ductal carcinoma; ILC, invasive lobular carcinoma; siRNA, small interfering RNA; TBS, TRIS buffer saline; VCAM-1, vascular cell adhesion molecule-1

*Contributed equally

Key words: breast cancer, blood vessels, endothelium activation, immunity
Altogether, these results provide further results that egfl7 serves a regulatory role in endothelial cell activation in relation to immune infiltration and that it is a potential therapeutic target to consider for improving anticancer immunotherapies.

\section{Introduction}

The main therapeutic achievements in treating cancer have been historically obtained by limiting cancer cell proliferation or division using non-specific, thereafter, targeted therapies against these cells. More recently, an increasing interest has emerged on the role of the tumor microenvironment in the development of cancer lesions (1). Within this microenvironment, immune cells which can mediate the destruction of cancer cells and the immune system as a whole offer a number of novel potential targets for additional therapies (2), a proportion of which have provided practical applications for treating patients. The first efficient treatments using immunotherapies targeting PD-1/PD-L1 were beneficial for patients with melanoma (3) and such treatments were recently approved for treating lung cancer as well (4). Blood vessels, which are part of the tumor microenvironment and already the targets of anti-angiogenic drugs in clinical practice for treating colon or lung cancers, also serve a crucial role as a natural physical barrier which regulates the immune response. Indeed, endothelial cells which line the inner side of blood vessels, regulate the extravasation of circulating immune cells into tissues. Under non-activated, normal conditions, endothelial cells form a non-adhesive surface which does not allow for strong interactions with circulating immune cells (5). Upon stimulation by pro-inflammatory cytokines, endothelial cells become activated and express high levels of cell surface leukocyte adhesion molecules such as E- and P-selectin, intercellular adhesion molecule-1 (ICAM-1) and vascular cell adhesion molecule-1 (VCAM-1). These molecules participate in the capture of circulating immune cells through the rolling, arrest, firm adhesion, and extravasation of leukocytes from the circulation toward the tissues (5). This process is particularly important in the context of cancer where activation of endothelial cells directly controls the penetration of cytotoxic immune cells in the tumor foci $(6,7)$. The gene coding for EGF-like domain-containing protein 7 (egfl7) is mainly expressed 
in blood vessel endothelial cells (8-10) and its expression is deregulated in human cancer. High expression levels of egfl7 were correlated with a more advanced stage of human colon cancer (11), with poor survival in human hepatocarcinoma (12), and with a higher tumor grade in human gliomas (13). Egfl7 expression was also associated with poor overall survival in human pancreatic cancer (14). Furthermore, a previous study demonstrated in breast cancer tissue samples that a high egfl7 protein score in cancer cells corresponded with low VCAM-1, ICAM-1, and interferon- $\gamma$ in the tumors (15). Using experimental approaches, it has been demonstrated that, when expressed by tumor cells, egfl7 promotes tumor escape from immunity by downregulating the activation of tumor blood vessels (15). Egfl7 expressed constitutively by blood vessel endothelial cells continuously inhibits the expression of leukocyte-adhesion cell surface receptors and thus limits endothelium activation. In the context of cancer, egfl7 expressed by tumor blood vessels similarly prevents the cytotoxic immune cells from entering the tumor mass, thus protecting tumor from immune destruction (15).

To the best of our knowledge, no previous study has addressed the role and expression of egfl7 in blood vessels of the tumor microenvironment. In the present study, a large cohort of human breast cancer lesions were included and the expression levels of egfl7 and that of ICAM-1 as a marker of endothelium activation, were evaluated in peritumoral vessels of human breast cancer samples.

\section{Materials and methods}

Human samples. The patient population is described in details in the main section. Human tissue samples were processed and stored at the pathology laboratory of the Centre Oscar Lambret cancer clinic (Lille, France). Following surgery, tissues were fixed in $4 \%$ paraformaldehyde and embedded in paraffin. For each tumor, analyses were performed on sections from the paraffin block which had been used for estrogen receptor, progesterone and HER2 expression analyses and for diagnosis, considered by the pathologists to be the most representative of the lesion.

Antibodies. For staining human tissues, a primary monoclonal rabbit anti-human ICAM-1 antibody (Abcam, Cambridge, UK; ab53013), a monoclonal mouse anti-human CD31 (DAKO \#M823, clone JC/70A), a monoclonal mouse anti-CD34 (DAKO \#M7165, clone QBend-10), and a goat biotinylated anti-rabbit IgG (BA-1000, Vector laboratories) were used. For staining mouse tissues, an anti-mouse ICAM-1 antibody (Abcam ab25375), an anti-rat-Alexa 488 antibody (Life Technologies A21208), and a biotinylated rat anti-mouse-CD31 (Pharmingen 553371) were used. Antibodies were reconstituted and stored according to the manufacturers' recommendations.

Immunostaining of human tumor samples. Four successive paraffin sections $(4-\mu \mathrm{m})$ were prepared from each sample paraffin block and laid on superfrost + slides, dried overnight at $56^{\circ} \mathrm{C}$, and rehydrated before staining. For ICAM-1 staining, slides were placed in methanol, $0.3 \% \mathrm{H}_{2} \mathrm{O}_{2}$ for $20 \mathrm{~min}$ at room temperature, rinsed in TRIS- $\mathrm{HCl} 10 \mathrm{mM}, \mathrm{pH} 7.5, \mathrm{NaCl} 0.15 \mathrm{M}$ (TRIS buffer saline, TBS) for $5 \mathrm{~min}$, incubated in Antigen retrieval, solution citrate (Vector Laboratories, Peterborough, $\mathrm{UK}$ ) for $20 \mathrm{~min}$ at $90^{\circ} \mathrm{C}$, then for $20 \mathrm{~min}$ at room temperature, and rinsed twice in TBS. Slides were incubated in TRIS-HCl $0.1 \mathrm{M}, \mathrm{pH} 7.5, \mathrm{NaCl} 0.15 \mathrm{M}, 20 \%$ goat serum, $0.5 \%$ blocking buffer from TSA Biosystem (Perkin Elmer, Beaconsfield, UK) for $2 \mathrm{~h}$ and incubated in rabbit anti-human ICAM-1 (1:200) overnight at $4^{\circ} \mathrm{C}$ in a humidified atmosphere. Slides were then washed in TBS for 5 min twice and incubated in goat biotinylated anti-rabbit $\operatorname{IgG}(1: 250)$ for $45 \mathrm{~min}$. Slides were then washed three times in TBS for $5 \mathrm{~min}$, incubated in Streptavidin-A-HRP (TSA Biosystem kit, 1:100) in blocking buffer for $30 \mathrm{~min}$, washed 3 times in TRIS-HCl $0.1 \mathrm{M}, \mathrm{pH} 7.5, \mathrm{NaCl}$ $0.15 \mathrm{M}$, Tween-20 $0.25 \%$ (TNT) for $5 \mathrm{~min}$, then incubated in biotinylated tyramine (1:50) in amplification buffer (TSA Biosystem, Perkin Elmer), washed 3 times in TNT for 5 min, incubated in streptavidin-A-HRP (TSA Biosystem kit, Perkin Elmer, 1:100) in blocking buffer for $30 \mathrm{~min}$, washed twice in TNT for $5 \mathrm{~min}$ and the immune complexes revealed using DAB kit (Vector Laboratories) under microscope observation. Staining was stopped with tap water and slides counterstained with hemalun, dehydrated and mounted.

CD31 and CD34 immunostainings were performed using a BenchMark ULTRA automat and dedicated reagents (Ventana Medical Systems, Roche Diagnostics, Basel, Switzerland). For CD31 staining, slides were deparaffinized, incubated at $95^{\circ} \mathrm{C}$ for $36 \mathrm{~min}$ in cell conditioning buffer 1, washed in Reaction Buffer. Endogenous peroxydases were inactivated using UV INHIBITOR for 4 min and slides further washed in Reaction Buffer. Slides were then incubated in anti-CD31 (Dako, Agilent Technologies, Inc., Santa Clara, CA, USA, \#M0823, 1:20) for $28 \mathrm{~min}$, rinsed in Reaction Buffer and incubated in HRP UNIV MULT for $8 \mathrm{~min}$, washed in Reaction Buffer, developed using UV DAB and counterstained in Hematoxylin for $4 \mathrm{~min}$, then in Bluing Reagent, washed in Reaction Buffer before dehydration and mounted. For CD34 staining, slides were processed similarly except that the cell conditioning buffer 1 treatment was performed for $8 \mathrm{~min}$ and the slides were incubated with mouse anti-CD34 (DAKO, clone QBend-10, 1:50) for $20 \mathrm{~min}$.

Stained slides were analyzed by two independent oncologists, including a breast cancer pathologist, using an Axioplan 2 microscope (Zeiss) and compared to the corresponding hematoxylin/phloxin safran-stained slides used for identification of the tumor sub-regions for diagnosis. Image acquisition was done using the ZEN2012 blue edition software (Carl Zeiss AG, Oberkochen, Germany).

In situ hybridization. Paraffin sections $(4-\mu \mathrm{m})$ were laid on superfrost + slides and dried overnight at $56^{\circ} \mathrm{C}$. Digoxigenin-labelled sens and anti-sens egfl7 probes were prepared from a pCMV-sport 6 plasmid containing the full length human egfl7 cDNA using the Riboprobe Gemini system II kit (Promega Corporation, Inc., Madison, WI, USA). Slides were processed using a Ventana Discovery automat as described previously (8).

Cell transfection, reverse transcription-quantitative polymerase chain reaction ( $R T-q P C R)$. Primary human umbilical vein endothelial cells (Lonza Biologics PLC, Slough, UK) were cultured in EGM-2 medium and passaged according to the 
manufacturers' recommendations. Cells $\left(4 \times 10^{4} /\right.$ well) between passage 2 and 5 were plated in $0.33 \mathrm{~cm}^{2}$ wells and transfected with $50 \mathrm{nM}$ non-targeting small interfering RNA (siRNA, siCtrl, D-001810-01, Dharmacon, Inc., Lafayette, CO, USA), or with siRNA targeting egfl7 [siEgfl7, J-015668-10, Dharmacon, Inc., $(15,16)]$ or ICAM-1 (siICAM-1, L-003502-00 Dharmacon, Inc.) using Lipofectamine RNAiMax (Life Technologies, ThermoFisher Scientific, Inc., Waltham, MA, USA). Three days later, the cells were lysed and total RNA isolated using the Nucleospin RNA kit and reagents (Macherey-Nagel, Düren, Germany). RNA were quantified using a Nanodrop (ThermoFisher Scientific, Inc.) and RT was performed using the High Capacity Reverse Transcription kit (Life Technologies, ThermoFisher Scientific, Inc.). qPCR was performed in duplex reactions, mixing TaqMan FAM-labelled probes for human egfl7 (Hs00211952_m1) or for ICAM-1 (Hs00164932.m1) with the normalizing 32 -microglobulin (B2M) VIC-labelled probe in the same tube and processed in a StepOne machine. Data were expressed as $2^{-\Delta \Delta \mathrm{Cq}}$ where $\Delta \mathrm{Cq}=\mathrm{Cq}$ of gene-Cq of $\mathrm{B} 2 \mathrm{M}$, and $\Delta \Delta \mathrm{Cq}=\Delta \mathrm{Cq}$ sample- $\Delta \mathrm{Cq}$ control.

Ethics. Sample storage, handling and analysis were performed according to the European regulations and the Helsinki Declaration. Patient consent and legal authorizations were obtained for all the analyses performed and for the processing of patients personal data. The protocol was approved by the 'Comite de Protection des Personnes Nord-Ouest IV' on January 12, 2010.

Statistical analysis. All statistical analysis was performed using STATA 11.2 statistical software (StataCorp, College Station, TX, USA). Analyses used Chi2 and Fisher's exact tests for categorical data and Kruskall-Wallis test for continuous variables and Cuzick's test for trend across ordered groups. $\mathrm{P}<0.05$ was considered to indicate a statistically significant difference.

\section{Results}

Patient population. Patients included in the present study underwent surgery for breast cancer at the Oscar Lambret Center cancer clinic between January 1st, 2005 and July 31st, 2005, for histologically-proven invasive ductal carcinoma (IDC), invasive lobular carcinoma (ILC), or ductal carcinoma in situ (DCIS). Patients were at least 18 years-old, had not been previously treated with chemotherapy, and had not received neo-adjuvant chemotherapy. Patients whose tumors exhibited a histology-proven lobular carcinoma in situ were excluded from the study. The cohort therefore included: 30 DCIS and 174 invasive carcinomas, among which 131 IDC (64.2\%, Table I), 27 ILC (13.2\%), and 16 others types (tubular carcinoma, apocrine, or neuroendocrine carcinoma, 7.8\%). The population was composed of 39 stage 1 (22.4\%), 98 stage 2 (56.3\%), and 37 stage 3 carcinomas (21.2\%). Among invasive cancers, 20 (11.5\%) exhibited HER2 gene amplification as defined by a $3+$ score using immunohistochemistry or $>=2+$ score when using chromogenic in situ hybridization. Hormonal receptors were positive as defined by estrogen receptor $>=10 \%$ and/or progesterone receptor $>=10 \%$ in $85.8 \%$ of cases. A total of 13 triple negative breast cancer (7.5\%), as defined by estrogen and progesterone receptor
Table I. Patient population.

\begin{tabular}{|c|c|c|}
\hline Tumors & $\mathrm{N}$ & $\%$ \\
\hline Histological type & 204 & 100 \\
\hline IDC & 131 & 64.2 \\
\hline ILC & 27 & 13.2 \\
\hline DCIS & 30 & 14.7 \\
\hline Other & 16 & 7.8 \\
\hline SBR grade & 174 & 100 \\
\hline 1 & 39 & 22.4 \\
\hline 2 & 98 & 56.3 \\
\hline 3 & 37 & 21.3 \\
\hline TNM classification & 166 & 100 \\
\hline $\mathrm{T}$ & 13 & 7.5 \\
\hline T0-T1a & 42 & 24.1 \\
\hline $\mathrm{T} 1 \mathrm{~b}$ & 65 & 37.4 \\
\hline T1c & 43 & 24.7 \\
\hline T2 & 3 & 1.7 \\
\hline \multicolumn{3}{|l|}{ T3 } \\
\hline TNM classification & 204 & 100 \\
\hline $\mathrm{N}$ & 112 & 54.9 \\
\hline NO & 59 & 28.9 \\
\hline N1 & 4 & 1.9 \\
\hline $\mathrm{N} 2$ & 8 & 3.9 \\
\hline N3 & 21 & 10.3 \\
\hline \multicolumn{3}{|l|}{$\mathrm{Nx}$} \\
\hline Hormonal receptor & 204 & 100 \\
\hline HR+ & 175 & 85.8 \\
\hline HR- & 26 & 12.7 \\
\hline UK & 3 & 1.5 \\
\hline HER2 status & 174 & 100 \\
\hline Negative & 151 & 86.8 \\
\hline Positive & 20 & 11.5 \\
\hline Unknown & 3 & 1.7 \\
\hline Triple negative & $13 / 174$ & 7.5 \\
\hline
\end{tabular}

DCIS, ductal carcinoma in situ; IDC, invasive ductal carcinoma; ILC, invasive lobular carcinoma; HR, hormonal receptor; TNM, Tumor node metastasis; SBR, Scarf-Bloom-Richardson.

equal to zero associated with Her2 negative expression, were identified within this cohort.

Parallel tissue sections were prepared for the positive identification of blood vessels, for the quantitation of activated vessels among the identified blood vessels, and for the quantitation of egfl7 expression levels in the same tumor areas. The analysis was concentrated on peritumoral vessels and the tumor sample block which had been used for the initial diagnosis of the patient's lesion was selected, thus being the most representative and the closest tissue to the tumor.

Identification of blood vessels. In order to quantify the activated blood vessels in peritumoral areas, the initial step was to establish a staining procedure for positively identifying 

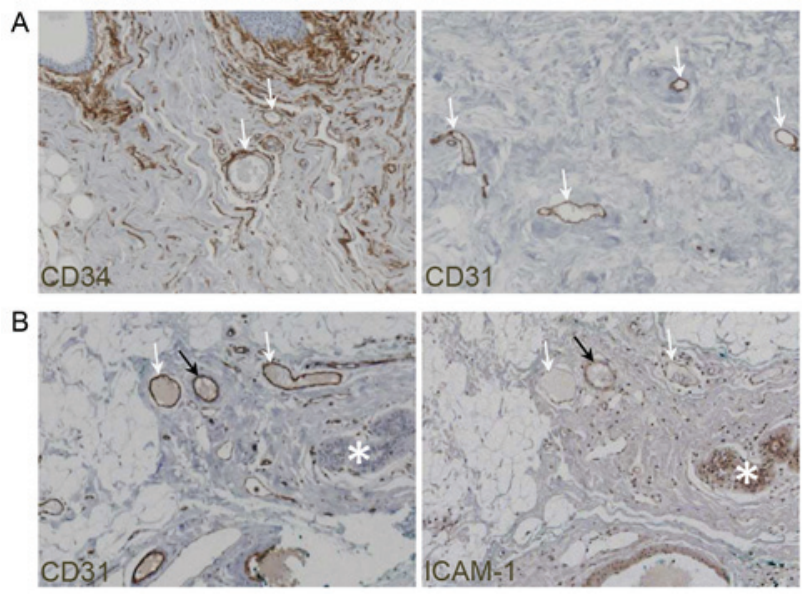

Figure 1. Identification of blood vessels in human breast cancer lesions (A) Immunohistochemistry of human breast cancer lesions stained using an anti-CD34 antibody (left) and an anti-CD31 antibody (right). Staining appears as a brown pigment. Arrows: Blood vessels identified as stained structures with a lumen and containing blood cells. (B) Immunohistochemistry on parallel sections of the peritumoral region of a human breast cancer lesion using an anti-CD31 (left) antibody which marks blood vessels (arrows). ICAM-1 staining of the same area reveals ICAM-1 ${ }^{+}$activated blood vessels (black arrow) and ICAM-1 non-activated blood vessels (white arrows). Asterisk indicates cancer cells. ICAM-1, intercellular adhesion molecule-1.

blood vessels in the human tissue sections. For this purpose, immunostaining using anti-CD34 and anti-CD31 antibodies were compared, as both are widely used markers of endothelial cells (17). Staining human breast cancer samples with either antibody clearly revealed the blood vessels (Fig. 1A) but staining for CD31 provided a more specific signal and gave rise to a much lower background than staining for CD34, which also stained non-vascular structures. Therefore all breast cancer tissue sections were subsequently identified with CD31 staining and blood vessels were positively identified as $\mathrm{CD} 31^{+}$structures.

Identification of activated blood vessels in peritumoral areas. Activated blood vessel endothelial cells in breast cancer samples were identified following ICAM-1 immunostaining. ICAM-1 staining was membranous in endothelial cells. Its expression in vascular structures was confirmed by checking the CD31 staining in parallel sections of the same area (Fig. 1B). In case of an absence of ICAM-1+ vessels and in order to dismiss any technical artifact on a specific sample, ICAM-1 $1^{+}$staining was verified on lobular islets or galactophoric channels of the same sample, as these structures also stain for this marker. The percentage of ICAM-1+ activated vessels compared with ICAM-1- non-activated vessels, was evaluated and scored. Score 0 was defined as no ICAM- $1^{+}$vessels, scores $1+, 2+$, and $3+$ were defined by $1-29 \%, 30-60 \%$ and $>60 \%$ of ICAM-1 $1^{+}$vessels, respectively. Activation of blood vessels was heterogeneous within any given tumor, as vessels displayed different states of activation in the same sample depending on their location and on their size (Figs. 1B and 2). Among the 175 cases analyzed for ICAM-1, 68 lesions (38.9\%) were scored 0 for ICAM-1, $62(35.4 \%)$ were scored 1+, 28 (16.0\%) were scored $2+$ and 17 (9.7\%) were scored 3+. A significant correlation was not identified between ICAM-1 expression

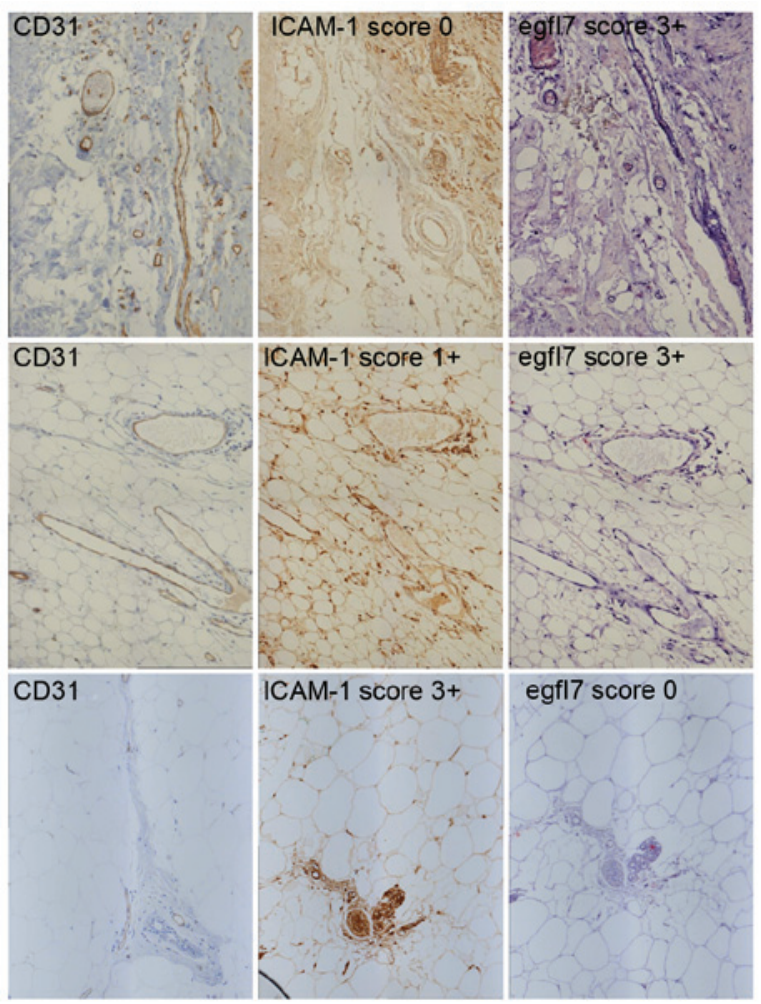

Figure 2. Scoring of ICAM-1 and of egfl7 staining in human breast cancers. Illustration of parallel sections of 3 different breast cancer lesions (top: IDC, middle: mixed ductal and lobular carcinoma, bottom: IDC) after CD31 (left) and ICAM-1 (center) protein staining (immunohistochemistry) and egfl7 (in situ hybridization, right). Scores for ICAM-1 and Egfl7 are indicated. ICAM-1, intercellular adhesion molecule-1; egfl7, EGF-like domain-containing protein 7 .

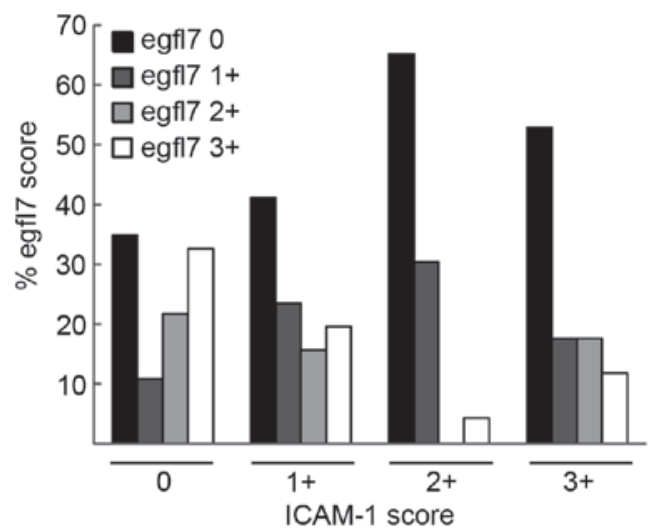

Figure 3. Distribution of egfl7 scores within the ICAM-1 sub-groups in human breast cancers. Percentage of each egfl7 score within each of the ICAM-1 subgroups, as determined by immunohistochemistry analysis. ICAM-1, intercellular adhesion molecule-1; egfl7, EGF-like domain-containing protein 7.

in peritumoral blood vessels and clinical data such as cancer type, grade, metastases, hormone receptors, and HER2 status, or with the triple-negative type, using the Chi2 test if theoretical size $\geq 5$ and Fisher exact test otherwise.

Blood vessels are less activated in areas where egfl7 is highly expressed. Regarding egfl7 transcript detection using in situ hybridization, positive cases were defined based on the nuclear 
Table II. Correlations between ICAM-1 scores and egfl7 scores.

\begin{tabular}{|c|c|c|c|c|c|c|c|c|c|c|c|}
\hline & \multicolumn{8}{|c|}{ ICAM-1 score } & & & \\
\hline & \multicolumn{2}{|c|}{$0(0 \%)$} & \multicolumn{2}{|c|}{$1+(0-29 \%)$} & \multicolumn{2}{|c|}{$2+(30-60 \%)$} & \multicolumn{2}{|c|}{$3+(>60 \%)$} & \multicolumn{2}{|c|}{ Total } & \multirow[b]{2}{*}{$\mathrm{P}$} \\
\hline & $\mathrm{n}$ & $\%$ & $\mathrm{n}$ & $\%$ & $\mathrm{n}$ & $\%$ & $\mathrm{n}$ & $\%$ & $\mathrm{n}$ & $\%$ & \\
\hline egfl7 score & & & & & & & & & & & Fisher exact \\
\hline $0(0 \%)$ & 16 & 26.2 & 21 & 34.4 & 15 & 24.6 & 9 & 14.8 & 61 & 100.0 & $\mathrm{P}=0.015$ \\
\hline $1+(0-29 \%)$ & 5 & 18.5 & 12 & 44.4 & 7 & 25.9 & 3 & 11.1 & 27 & 100.0 & \\
\hline $2+(30-60 \%)$ & 10 & 47.6 & 8 & 38.1 & 0 & 0.0 & 3 & 14.3 & 21 & 100.0 & Test for trend \\
\hline $3+(>60 \%)$ & 15 & 53.6 & 10 & 35.7 & 1 & 3.6 & 2 & 7.1 & 28 & 100.0 & $\mathrm{P}=0.004^{\mathrm{a}}$ \\
\hline Total & 46 & 33.6 & 51 & 37.2 & 23 & 16.8 & 17 & 12.4 & 137 & 100.0 & $\mathrm{P}=0.001^{\mathrm{b}}$ \\
\hline
\end{tabular}

${ }^{a}$ Test for trend for ICAM-1 according to egfl7 and for begfl7 according to ICAM-1. ICAM-1, intercellular adhesion molecule-1; egfl7, EGF-like domain-containing protein 7.

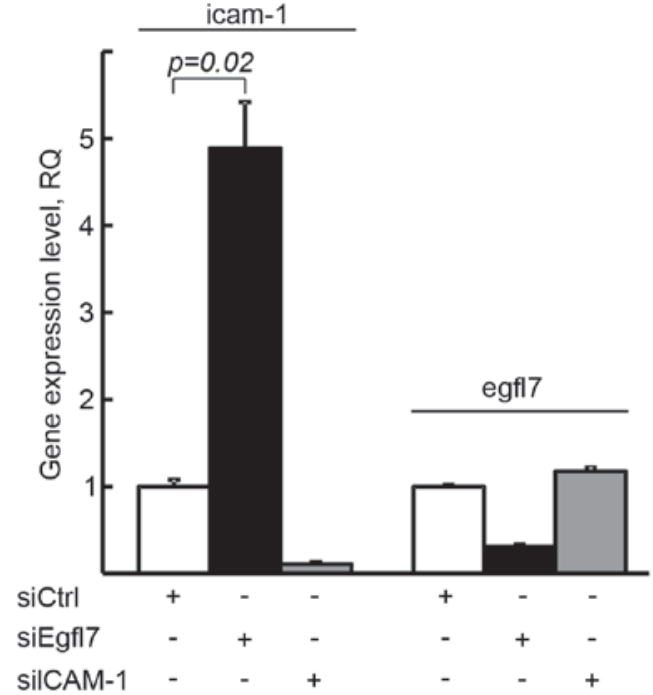

Figure 4. Egfl7 regulates ICAM-1 expression in endothelial cells in vitro. Expression levels of ICAM-1 and of egfl7 transcripts measured by duplex reverse transcription-quantitative polymerase chain reaction in human umbilical vein endothelial cells transfected with siCtrl (white bars), siEgfl7 (black bars) or siICAM-1 (gray bars). The results are expressed as RQ over siCtrl values, data are expressed as $2^{-\Delta \Delta C T}$ using B2M levels as normalizing value measured in each sample. The results are representative of 2 experiments performed in triplicates. Error bars represent standard deviation of the mean. ICAM-1, intercellular adhesion molecule-1; egf17, EGF-like domain-containing protein 7; RQ, relative quantities.

staining of endothelial cells and scoring was made using the same criteria as for ICAM-1 staining. Among the 148 cases analyzed for egfl7 expression, $63(42.6 \%)$ were scored 0 , $30(20.3 \%)$ were scored $1+, 27(18.2 \%)$ were scored $2+$ and $28(18.9 \%)$ were scored $3+$. A significant correlation was not identified between egfl7 expression in peritumoral area and clinical data including cancer type, grade, metastases, hormone receptors, nor HER2 status using the Chi2 test if theoretical size $\geq 5$ and Fisher exact test otherwise.

However, a strong and significant correlation was apparent between the ICAM-1 scores and the egfl7 scores in the analyzed lesions $(\mathrm{P}=0.015$, Fisher exact test). Cuzick's tests for trend demonstrated that when the ICAM-1 score increased, the egfl7 score decreased (Fig. 3, P=0.004, Table II), and vice-versa $(\mathrm{P}=0.001$, Table II). These observations directly implied that, regardless of the type and grade of breast cancer lesions, the expression levels of ICAM-1 and those of egfl7 were somehow linked.

Egfl7 regulates ICAM-1 expression but ICAM-1 does not affect egfl expression in endothelial cells. In order to assess which gene between ICAM-1 and egfl7 regulated the expression of the other one, we deregulated either egfl7 or ICAM-1 in human primary endothelial cells by RNA interference and checked for the expression of the other gene. Targeting egfl7, which lowered its expression by $69.4 \%$, induced a 4.9 -fold increase in ICAM-1 expression levels in the same cells. On the other hand, the downregulation of ICAM-1 expression levels by $89.3 \%$ did not significantly affect the expression levels of egfl7 in the same cells (Fig. 4). Thus, these results show that egfl7 constitutively represses the expression of ICAM-1 in endothelial cells but that ICAM-1 does not regulate egfl7 expression.

\section{Discussion}

We have previously shown that egfl7 promotes the escape of tumors from immunity by repressing the activation of endothelial cells in mice (15). In this previous study, an inverse correlation between egfl7 protein levels and those of ICAM-1 were demonstrated in a limited number of human breast cancer lesions. The present study represents the first study of the correlation between the expression of egfl7 and that of ICAM-1 in a large population of patients which allowed for statistical analysis. This population formed a representative sample of breast cancer subtypes close to what is typically described by pathologists in the global population, where $64 \%$ are IDC, $10 \%$ are ILC and $7 \%$ are of other types (mucinous, tubular) and where among the IDC, 19\% show a Scarf-Bloom-Richardson grade equal to 3 and are positive for hormonal receptors in $85 \%$ of cases, while HER 2 overexpression is detected in $10-15 \%$ of the cases (18). Since egfl7 is a secreted protein which can accumulate in distant tissues from 
the producing cells (16), egfl7 transcripts were selected to analyze using in situ hybridization rather than following the distribution of the egfl7 protein as before. Indeed, transcript analysis provides a direct visualization of egfl7-expressing cells in tumor samples. Furthermore, the study was focused on the activation of endothelial cells in the tumor microenvironment, i.e. in peri-tumoral areas of human breast cancer lesions and on a possible correlation between endothelium activation and expression levels of egfl7. For that matter, the analyzed area selected was in the periphery of the main infiltrating lesion, not close to an in situ carcinoma focus or a glandular islet, not within a necrotic zone, nor within any healing zone consecutive to biopsy, so as to avoid any possible inflammation and activation of blood vessels other than those due to the presence of the main tumor. In order to identify vascular vessels without any ambiguity, the choice of a good histological marker was important. CD34 is a transmembrane glycoprotein expressed in hematopoietic stem cells, endothelial cells, in fibroblasts, and in stromal cells. It is commonly used as a marker for endothelia in pathology labs, though it is not specific to this tissue (19). CD31 (or platelet-endothelial cell adhesion molecule-1) is a cell membrane protein expressed by endothelial cells, platelets, and hematopoietic cells. It is more particularly expressed in endothelial cells (17) and is widely used for visualizing these cells in animal models. It should however be noted that although both markers reveal endothelial cells, neither one is strictly specific for blood vessels. The positive identification of blood vessels was therefore achieved by crossing the CD31 staining information with the identification of vessels by the breast cancer pathologist and the oncologist on the base of morphological criteria, so as to exclude any potential non-vascular CD31+ ${ }^{+}$structure.

Previous studies have addressed the expression of ICAM-1 in breast cancer lesions but with different aims (20-23). Higher levels were correlated with a more aggressive tumor phenotype (20) and an increased ICAM-1 staining has been observed in blood vessels of breast cancer tissues compared to normal tissues (21). Furthermore, fewer numbers of leukocytes infiltrated in ductal breast carcinoma were also associated with lower levels of ICAM-1 expression on tumor endothelial cells (22). More recently, ICAM-1 has been identified as a marker for triple negative breast cancers and shown to be a promising target for treating these tumors (23). All these studies were focused on the expression of ICAM-1 in the tumor but did not specifically address the expression of ICAM-1 in the tumor microenvironment excluding the tumor area in itself, thus leading to different results. We have previously reported that egfl7 protein expression was associated with improved prognosis factors in human breast cancer lesions (24) but this previous study also focused on egfl7 expression in cancer areas, not peritumoral areas focused on in the present study. A correlation between egfl7 protein expression in tumoral foci with lower grade and hormonal receptor expression was identified (24), but there was no evidence that expression of egfl7 transcripts in peritumoral vessels could be correlated with any of these prognosis factors, thus confirming the fact that the localization of egfl7 protein secreted within tumor areas and the expression of its transcripts in peri-tumoral blood vessels are apparently not linked. Notably, in the present study, egfl7 transcripts were identified in cancer cells, demonstrating that these cells also produce egfl7 although it is predominantly an endothelial gene in normal tissues (8-10). This suggests that the Egfl7 protein detected in the earlier study (24) was at least in part produced by cancer cells themselves.

The most interesting observation made in the present study was the inverse correlation between the expression levels of egfl7 and those of ICAM-1 in the tumor microenvironment. This correlation was due to the fact that egfl7 regulates the expression of ICAM-1 in endothelial cells and not the reverse. This confirmed previous observations that egfl7 negatively regulates the expression of ICAM-1 (15) while, on the other hand, the potential effects of ICAM-1 on egfl7 expression have never previously been reported. ICAM-1 expression is mainly regulated by the NFkB and the MAPK/Erk pathways (25-28). It is most probable that Egfl7 regulates the expression of ICAM-1 through the NFkB pathway in the breast cancer microenvironment similarly to in coronary endothelial cells where Egfl7 treatment reduced a cyclosporin A-induced increase in $\mathrm{NF \kappa B}$ activity and ICAM-1 expression (29), but such regulation is not yet demonstrated.

The results of the present study underline the important role served by egfl7 in the regulation of the activation of blood vessels in cancer lesions. They suggest that egfl7 may be a valuable therapeutic target to consider in order to enhance the efficiency of immune therapies against cancer. As a matter of fact, targeting egfl7 has been shown to increase tumor blood vessel damage and to enhance the tumor response to anti-VEGF treatment in various murine models (30) but the effects on the infiltration of immune cells into the tumors has not been assessed. Whether an anti-egfl7 therapy would increase the efficiency of immunotherapies in treating cancer remains to be assessed. Understanding the mechanisms of endothelium activation in cancer may allow for an improved selection of patients which could benefit from immunotherapies. Regarding breast cancer, this would be particularly pertinent for the highly heterogeneous triple negative population, which would appear to be a good candidate for such refinement in diagnosis.

\section{Acknowledgements}

The present study was supported by Ligue Régionale contre le Cancer, Institut National du Cancer (grant no. INCA_6598), and Fondation ARC (grant no. SFI20111203644). Dr Fabrice Soncin is Directeur de Recherche of the Institut National de la Santé et de la Recherche Médicale.

\section{References}

1. Hanahan D and Weinberg RA: Hallmarks of cancer: The next generation. Cell 144: 646-674, 2011.

2. Chen DS and Mellman I: Oncology meets immunology: The cancer-immunity cycle. Immunity 39: 1-10, 2013.

3. Topalian SL, Hodi FS, Brahmer JR, Gettinger SN, Smith DC, McDermott DF, Powderly JD, Carvajal RD, Sosman JA, Atkins MB, et al: Safety, activity, and immune correlates of anti-PD-1 antibody in cancer. N Engl J Med 366: 2443-2454, 2012.

4. Brahmer J, Reckamp KL, Baas P, Crinò L, Eberhardt WE, Poddubskaya E, Antonia S, Pluzanski A, Vokes EE, Holgado E, et al: Nivolumab versus docetaxel in advanced squamous-cell non-small-cell lung cancer. N Engl J Med 373: 123-135, 2015.

5. Muller WA: Mechanisms of transendothelial migration of leukocytes. Circ Res 105: 223-230, 2009. 
6. Herberman RB, Nunn ME, Holden HT and Lavrin DH: Natural cytotoxic reactivity of mouse lymphoid cells against syngeneic and allogeneic tumors. II. Characterization of effector cells. Int J Cancer 16: 230-239, 1975.

7. Shrikant $P$ and Mescher MF: Control of syngeneic tumor growth by activation of CD8+ T cells: Efficacy is limited by migration away from the site and induction of nonresponsiveness. J Immunol 162: 2858-2866, 1999.

8. Soncin F, Mattot V, Lionneton F, Spruyt N, Lepretre F, Begue A and Stehelin D: VE-statin, an endothelial repressor of smooth muscle cell migration. Embo J 22: 5700-5711, 2003.

9. Parker LH, Schmidt M, Jin SW, Gray AM, Beis D, Pham T, Frantz G, Palmieri S, Hillan K, Stainier DY, et al: The endothelial-cell-derived secreted factor Egfl7 regulates vascular tube formation. Nature 428: 754-758, 2004.

10. Fitch MJ, Campagnolo L, Kuhnert F and Stuhlmann H: Egfl7, a novel epidermal growth factor-domain gene expressed in endothelial cells. Dev Dyn 230: 316-324, 2004.

11. Diaz R, Silva J, Garcia JM, Lorenzo Y, García V, Peña C, Rodríguez R, Muñoz C, García F, Bonilla F and Domínguez G: Deregulated expression of miR-106a predicts survival in human colon cancer patients. Genes Chromosomes Cancer 47: 794-802, 2008.

12. Wu F, Yang LY, Li YF, Ou DP, Chen DP and Fan C: Novel role for epidermal growth factor-like domain 7 in metastasis of human hepatocellular carcinoma. Hepatology 50: 1839-1850, 2009.

13. Huang CH,Li XJ,Zhou YZ, Luo Y, Li C and Yuan XR: Expression and clinical significance of Egfl7 in malignant glioma. J Cancer Res Clin Oncol 136: 1737-1743, 2010.

14. Zhou L, Li J, Zhao YP, Guo JC, Cui QC, Zhou WX, Zhang TP, Wu WM, You L and Shu H: Prognostic significance of epidermal growth factor-like domain 7 in pancreatic cancer. Hepatobiliary Pancreat Dis 13: 523-528, 2014.

15. Delfortrie S, Pinte S, Mattot V, Samson C, Villain G, Caetano B, Lauridant-Philippin G, Baranzelli MC, Bonneterre J,Trottein F, et al: Egfl7 promotes tumor escape from immunity by repressing endothelial cell activation. Cancer Res 71: 7176-7186, 2011.

16. Lelièvre E, Hinek A, Lupu F, Buquet C, Soncin F and Mattot V: VE-statin/egfl7 regulates vascular elastogenesis by interacting with lysyl oxidases. Embo J 27: 1658-1670, 2008.Can't

17. Miettinen M: Immunohistochemistry of soft tissue tumours - review with emphasis on 10 markers. Histopathology 64: 101-118, 2014.

18. Penault-Llorca F and Arnould L: Adjuvant breast cancer: Which clinical and pathological characteristics in 2007? Bull Cancer 97: 1421-1426, 2010 (In French).

19. Fina L, Molgaard HV, Robertson D, Bradley NJ, Monaghan P, Delia D, Sutherland DR, Baker MA and Greaves MF: Expression of the CD34 gene in vascular endothelial cells. Blood 75 $2417-2426,1990$
20. Schröder C, Witzel I, Müller V, Krenkel S, Wirtz RM, Jänicke F, Schumacher U and Milde-Langosch K: Prognostic value of intercellular adhesion molecule (ICAM)-1 expression in breast cancer. J Cancer Res Clin Oncol 137: 1193-1201, 2011.

21. Fox SB, Turner GD, Leek RD, Whitehouse RM, Gatter KC and Harris AL: The prognostic value of quantitative angiogenesis in breast cancer and role of adhesion molecule expression in tumor endothelium. Breast Cancer Res Treat 36: 219-226, 1995.

22. Bouma-ter Steege JC, Baeten CIM, Thijssen VL, Satijn SA, Verhoeven IC, Hillen HF, Wagstaff J and Griffioen AW: Angiogenic profile of breast carcinoma determines leukocyte infiltration. Clin Cancer Res 10: 7171-7178, 2004.

23. Guo P, Huang J, Wang L, Jia D, Yang J, Dillon DA, Zurakowski D, Mao H, Moses MA and Auguste DT: ICAM-1 as a molecular target for triple negative breast cancer. Proc Natl Acad Sci USA 111: 14710-14715, 2014

24. Philippin-Lauridant G, Baranzelli M-C, Samson C, Fournier C, Pinte S, Mattot V, Bonneterre J and Soncin F: Expression of Egfl7 correlates with low-grade invasive lesions in human breast cancer. Int J Oncol 42: 1367-1375, 2013.

25. Rao VN, Huebner K, Isobe M, Ar RA, Croce CM and Reddy ES: elk, tissue-specific ets-related genes on chromosomes X and 14 near translocation breakpoints. Science 244: 66-70, 1989.

26. Kuldo JM, Westra J, Asgeirsdóttir SA, Kok RJ, Oosterhuis K, Rots MG, Schouten JP, Limburg PC and Molema G: Differential effects of NF-\{kappa\}B and p38 MAPK inhibitors and combinations there of on TNF-\{alpha $\}$ - and IL-1\{beta $\}$-induced proinflammatory status of endothelial cells in vitro. Am J Physiol Cell Physiol 289: C1229-C1239, 2005.

27. Maeng YS, Min JK, Kim JH, Yamagishi A, Mochizuki N, Kwon JY, Park YW, Kim YM and Kwon YG: ERK is an anti-inflammatory signal that suppresses expression of NF-kappaB-dependent inflammatory genes by inhibiting IKK activity in endothelial cells. Cell Signal 18: 994-1005, 2006.

28. Zhou Z, Connell MC and MacEwan DJ: TNFR1-induced NF-kappaB, but not ERK, p38MAPK or JNK activation, mediates TNF-induced ICAM-1 and VCAM-1 expression on endothelial cells. Cell Signal 19: 1238-1248, 2007.

29. Badiwala MV, Guha D, Tumiati L, Joseph J, Ghashghai A, Ross HJ, Delgado DH and Rao V: Epidermal growth factor-like domain 7 is a novel inhibitor of neutrophil adhesion to coronary artery endothelial cells injured by calcineurin inhibition. Circulation 124 (11 Suppl): S197-S203, 2011.

30. Johnson L, Huseni M, Smyczek T, Lima A, Yeung S, Cheng JH, Molina R, Kan D, De Mazière A, Klumperman J, et al: Anti-Egfl7 antibodies enhance stress-induced endothelial cell death and anti-VEGF efficacy. J Clin Invest 123: 3997-4009, 2013. 